\title{
L. Description of an invention for elevating and depressing water, applicable to the use of canal locks, and for preventing the usual waste of water therein
}

\section{Mr. Robert Salmon}

To cite this article: Mr. Robert Salmon (1806) L. Description of an invention for elevating and depressing water, applicable to the use of canal locks, and for preventing the usual waste of water therein , Philosophical Magazine Series 1, 25:100, 324-329, DOI: $10.1080 / 14786440608563456$

To link to this article: http://dx.doi.org/10.1080/14786440608563456

$$
\text { 曲 Published online: } 18 \text { May } 2009 .
$$

Submit your article to this journal ए

Џll Article views: 2

Q View related articles ¿ 
caustic potash. The potash which I employed, melted alone in the same crucible, absolutely remained colourless.

I did not endeavour to determine the quantities with precision, but $\mathbf{I}$ am convinced that they were very different.

This observation agrees with the division established by M. Stengel among meltings, and may lead to exact experiments, serving to prove the ingenious conjectures of this metallurgist.

I have endeavoured in this memoir to prove that the orcs of spathic iron have not all of them an uniform composition.

That the refractory quality of some among them is owing to the great proportion of magnesia which they contain.

I have endeavoured to explain, by the properties of this earth, the different practices made use of in the iron works where this kind of ore is melted, and which practices have not been hitherto explained.

I certainly wish that new observations should confirm my conjectures; but if it is proved that I am deceived, I shall nevertheless congratulate myself on having called the attention of metallurgists to one of the most important objects of the science to which they belong.

L. Description of an Invention for elevating and depressing. Water, applicalle to the Use of Canal Locks, and for preventing the usual Waste of Water therein. By $M r$. Robert Salmon, of Wulurn

s1R,

For the inspection of the Socicty of Arts, \&c. I have forwarded my model, and you herewith receive inclosed a description thereof. The novelty of this mode of bringing into action a considerable force, will, I hope, appear; and I beg leave to observe, that, besides the principle being applicable to locks, it will apply to many other uses where a Jift or descent is required. It may also be right to observe,

- From Transartims of Socicty of Arts, \&c. 1806. The society voted Mr. Salmon the silver medal and ten guineas for this improvement.

that 
that the curve may be so constructed as to counteract the inclination of the load on the plane under any irregular operation; and, being so constructed, the load will in all cases be nearly as easily moved as if always running on a level surface.

I am, sir,

Your most obedient humble servant, Wuburn, April 23, 1805.

Robert Salmon.

Charles Taylor, Esq.

In fig. 3. (Plate VIII.) $\mathrm{C}$ is supposed to represent a canal lock of the common construction, whose lower gates $i, i$, open towards or into the lock, and its upper gates $k, k$, open towards the upper or higher level of the canal; D is a hollow caisson, or water-tight chest, which is fitted to a walled chamber or side-lock, so as to move freely up and down therein ; $i$ is an opening, which forms a connection between the lock and the caisson-chamber, and which can be closed by a shuttle fitted thereto, when required. Four standards $e, e, e, e$, are firmly fixed on the ground and walls of the lock and chamber; and four posts $c, c, c, c$, are fixed in the four corners of the caisson ; on each alternate pair of these standards and posts the frames $a$ and $l$ rest, as on so many fulcrums, or moveable joints ; the frame $b$ (fig. 1 and 2.) has $t$. 0 straight parallel bars of thin iron fixed thereto, and standing up above the same; the frame $a$ has two similar bars affixed to it, except that the top edges of these are hollowed into a curve, as shown in the figures. BA is a carriage loaded with two heavy leaden weights, and resting on four low brase whecls, having grooves in their circumferences, like sash-pulleys, to receive the iron bars upon the frames $b$ and $a$, so that the carriage can be drawn along upon them; the distance of the axles of their wheels is such, that when the wheels at Brest on the frame over two of the post $c, c$, the wheels at $A$ shall at the same time rest over the other two posts $c, c$, as shown in fig. 1 ; and when the wheels at $\mathrm{B}$ rest over two of the standards $e, e$, the wheels at $A$ shall at the same time rest over the other two standards $e, e$, in fig. 2 . In order to work the model, the 

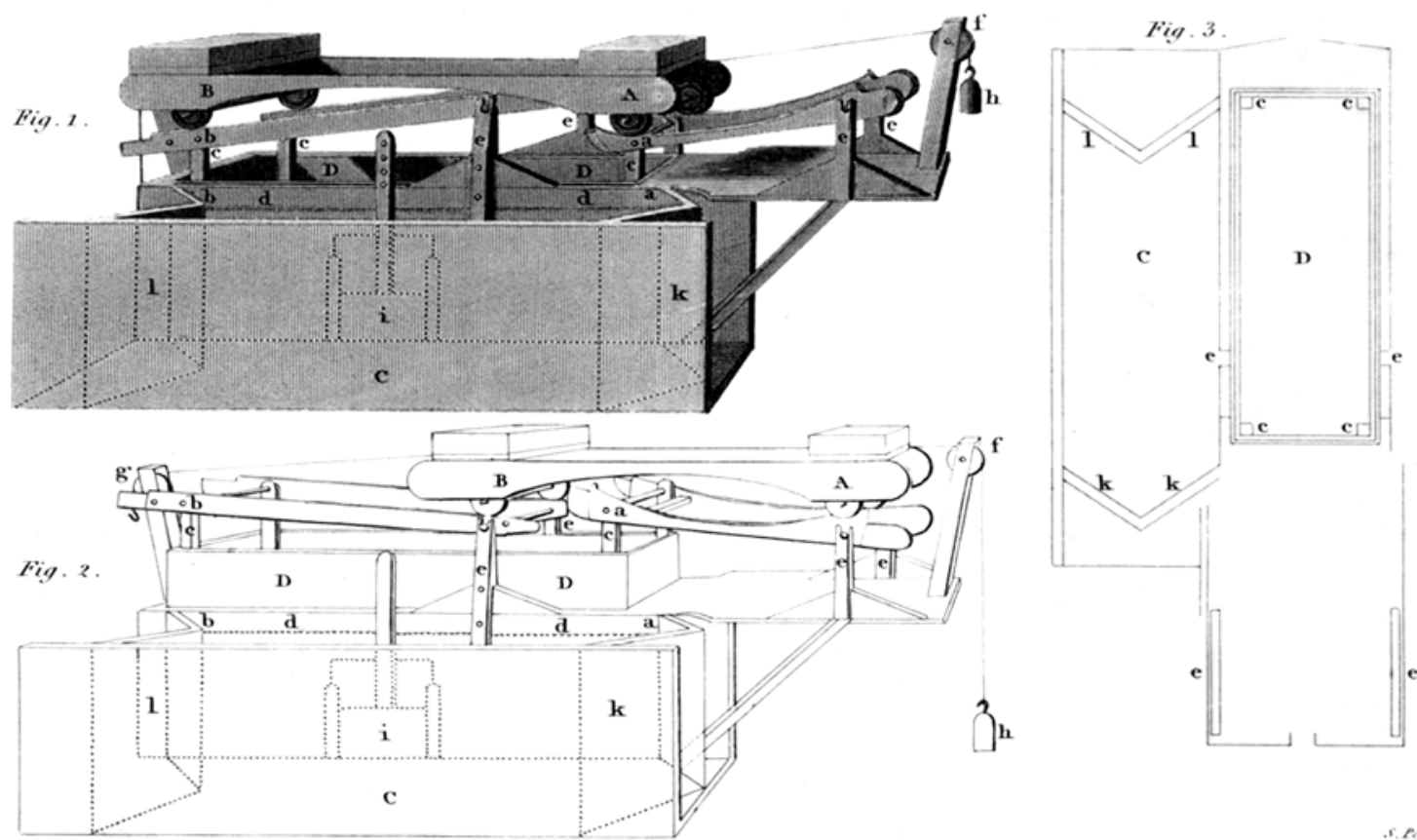
carriage must be brought into the position shown in fig. 1; and this can readily be done by stops, which are provided in the proper places on the curved bars, for preventing the wheels from rolling too far; as much water must then be poured into the lock $\mathrm{C}$, as will fill it exactly to the black line $d, d$, withinside the same; and if the taible on which the model stands be not levil, sinall wedges or chips must be put under the model where necessary, untl the surtace of the water exactly corresponds, all round the lock, with the top water-mark or line abcve mentioned: it must likewise be observed, to place the model across the table, so that the weight $h$, when hung over the pulley $f$ or $g$, may be at: liberty to descend. Then hang the two-pound weight $k$, fig. 1 , by the line over the pulley $f$, at the upper end of the lock; and the carriage, or load $B, A$, will be drawn forwards into the position shown at fig. 2 , and the water in the lock $\mathrm{C}$ will pass through the shuttle to buoy up the caisson $D$, and its surface in the lock will descend to the lower level. Again, by shifting the weight to the lower end $g$, the load will again be brought back, the caisson depressed, and the water forced through the shuttle, again raised to the higher level $d, d$, in the lock, as in fig. 1 .

Hence it is evident that the water in the lock, with or without a boat therein, may be raised or fowered, by the application of any force to move the carriage or lnad, horizontally on wheels. That when it is intented to pass a boat from the upper to the lower canal, the water in the lock is raised to the top water-level $d, d$; the upper gates $k, k$, are then readily opened, and the boat floated into the lock; this done, and these gates shut, the waier and boat, by withdrawing the load from the caisson, is lowered to the lower level of the canal. The lower gates $i, i$, are then opened, and the boat floated from the lock to the lower canal. In this operation of lowering a boat, it is evident, that so far from there being a waste of water, a weight of water equal to the boat and its load is raised from the lower to the upper canal ; for when the boat at the upper level first enters the lock, its own weight of water is displaced, and 
forced into the upper canal. And again, when it is floated into the lower canal, as much is again from that canal displaced, and forced into the lock.

On the same principle that water is gained by a descending buat, as above described, it will be observed that no waste ensues in an alternate passage; and that in an ascending passage a loss of water equal to the boat and its load only takes place.

It should be understood that as canals are sometimes more or less full of water, locks on this principle must be constructed to raise and depress, to the greatest extremes that ever happen, from the highest high-water to the lowest lowwater mark, and that being so constructed, they will apply to any intermediate heights; the curved plane $a$ being formed to adjust and counterbalance the inclination of the wheels on the other plane?, thereby maintaining an equilibrium, at any intermediate height, which the water in the canal may happen to be at.

Having described its manner of operating, I shall explain and compare cause and effect ; for which purpose it may be requisite first to state, that the load of the carriage $B, A$, is fifty-six pounds, which weight, when advanced, presses directly over the parts $c, c, c, c$, with all its gravity bearing on the caisson; but when the load is drawn forvards, it rests entirely on the fixed standards $e, c, e, e$, and by this change the whole effect is produced.

Now, if the model be set properly to work, it will be found, that a two-pound weight suspended over the pullcy at either end will put the carriage in motion, and thereby raise or depress the water in the lock, and that to do so, the two-pound weight will descend sixteen inches. Hence, two pounds descending sixteen inches may be denoted the cause or power to produce the effect. Further, it follows, that this two-pound weight descending sixteen inches produces the same operation as fifty-six pounds laid in the caisson would perform, and this sinking of the caisson D may be denoted the direct effect produced by the two-pound weight. The indirect and requisite effect being that of depressing or elevating the water in the lock $\mathrm{C}$, aud the com- 
parison thereon, will stand thus : the surface of a body of water of an area of twenty-four inches by ten, is raised about four inches and a half by the power of two pounds descending sixteen inches; and, vice vers $\hat{a}$, by reversing the power, the water is again depressed.

The shuttle $i$, between the lock and the caisson chamber, will regulate the time of the ascent or descent of the caisson. Woburn, April 23, 1805.

R. SALMON.

Charles Taylor, Esq.

SIR,

In reading over the copy of the paper which I hastily drew up, and sent with my model, I observe that I omitted making any remarks on its applicability, improvements to be made in the carriage to facilitate the moving of the load, and on the different other ways, besides the one shown in the model, by which it may be put in action.

It will readily occur to every engineer, that this sort of lock is not confined to the particular shape of the model, or to any particular form. The caisson-chamber may be placed endwise to the lock, may be of any shape, and placed at a nearer or further distance, as may be required.

On comparing the length and movements of the frames in the model with what may be required in practice, it will appear that the length of timbers at large will not be such but that strength sufficient may be obtained for any load. It is also evident, that, although the frames consist of only two bearers in the model, yet, at large, any number may be introduced parallel with each other, and as many wheets as bearers.

In this operation the weight of the carriage itself contributes towards the effect, which in common cases is otherwise, as generally there is an objection to the great weight required to make a carriage sufficiently strong for any extraordinary purpose ; and there is no doubt but, by an improvement of the carriage, it may be made to require much less than the power used in the present mudel. The mode I should pursue would be, to make the load in the wheels themselves; that is to say, the necessary load to produce the effect should be two solid iron cylinders running 
on as many bearers as are requisite, and to have a frame or carriage for the purpose only of connecting the cylinders; by these means the strength and friction of the axletrees would be reduced very much, and the means required then to perform the operation would be only to put the body in motion, and to oxercome any little obstacle or irregularity that the peripheries of the cylinders would meet with in their progress.

The advantage of rollers over wheels has been admitted even where the peripheries of the cylinders were in contact with the incumbent weight resting on the top of them, well as with the supporting plane below; but in the case above suggested they have more advantage, being only in contact with the upholding frames.

With respect to its operation, if any objections should be found to the great animal power that would at large be required, it will occur, that various other means may be used to put the carriage or load in motion; some without any loss of water, and others with a trifling loss, compared with what the lock holds. Thus, when the caisson is up, if, by a cock, a portion of water be let into it, the equilibrium will be destroyed, the caisson will sink, and the water in the lock be raised. Aggain, if by a pump, or other means, the water be returned from the caisson to the lock, the caisson will rise, and the load of itself recede, and this would be without waste of water. To put it in motion with a certain portion of waste, it is presumed different ways may be found; as the introduction of a portion of water from the upper canal to the lock, or the discharging of it from the lock to the lower level; these would, with management, occasion the eaisson to rise or fall; or, if a part of the load were made to shift further from, or nearer to, the fixed standards e eee, it would thereby cause the action required, and perform the operation; and it is probable tluat a better way than any here suggested would arise, should the thing be pot in practice.

I am, sir,

Your obedient humble servant,

Woburn, May 4, 1805.

Robert Salmon.

Charles Taylor, Esq. 